WP ECON 18.03

\title{
Estimation of competing risks duration models with unobserved heterogeneity using hsmlogit
}

\author{
David Troncoso-Ponce
}

Universidad Pablo de Olavide

Keywords: Duration analysis, Unobserved heterogeneity, d2 ml method, hshaz, hshaz2, hsmlogit, Hessian matrix, Multinomial Logit, Competing risks, Stata.

J EL Classification: C23, C25, C41, C54, C55, J64, J68. 


\title{
Estimation of competing risks duration models with unobserved heterogeneity using hsmlogit
}

\author{
David Troncoso Ponce \\ Pablo de Olavide University \\ Seville, Spain \\ Email: dtropon@upo.es
}

\begin{abstract}
.
This article presents hsmlogit, a new Stata command that estimates multispells discrete time competing risks duration models with unobserved heterogeneity. hsmlogit allows for the estimation of one, two and up to three competing risks, as well as a maximum of five points of support for the identification of unobserved heterogeneity distribution ([Heckman and Singer, 1984]). The main contribution of hsmlogit is that allows for exploiting the richness of large longitudinal micro datasets, by estimating competing risks duration models, instead of one-risk models (such as hshaz and hshaz2), as well as it takes into account the presence of unobserved heterogeneity affecting transition rates. In addition to this, and taking into account the larger size of longitudinal micro datasets used for the estimation of discrete time duration models, hsmlogit also provides the algebraic expressions of both first and second order derivatives that, respectively, define the gradient vector and Hessian matrix, which significantly reduce time required to achieve model convergence.
\end{abstract}

Keywords: Duration analysis, Unobserved heterogeneity, d2 ml method, hshaz, hshaz2, hsmlogit, Hessian matrix, Multinomial Logit, Competing risks models

\section{Acknowledgement}

I am greatful to professor Stephen Jenkins for his helpful comments and suggestions that have contributed to significantly improve this work, and for allowing me to use Stata code of his hshaz's command syntax. I also thank financial support of research project SEJ-6882 from Junta de Andalucía.

\section{Introduction}

Empirical estudies on individual decisions have experienced an important increase in recent years due to the boost of large and rich longitudinal micro datasets put available to the research community. Specially for the field of empirical Labor Economics focused on the estimation of labor market transition rates, the recent availability of large longitudinal micro datasets allows for capturing the presence of unobserved heterogeneity (UH, hereafter) components that affect the estimated transition rates. However, an important number of 
these empirical estudies that incorporates the presence of UH mainly focused on one-risk duration models, ${ }^{1}$ that analyze transition rates towards an only destination (for example, transitions from employment to unemployment, ignoring the existence of other destinations, such as inactivity, or finding another job). This article presents hsmlogit, a new Stata command that estimates multispells discrete time competing risks duration models with UH. hsmlogit allows for the estimation of one, two and up to three competing risks, as well as a maximum of five points of support for the identification of unobserved heterogeneity distribution ([Heckman and Singer, 1984]).

The main contribution of hsmlogit is that allows for exploiting the richness of large longitudinal micro datasets, by estimating competing risks duration models, instead of one-risk models (such as hshaz and hshaz2), as well as it takes into account the presence of unobserved heterogeneity affecting transition rates. In addition to this, and taking into account the larger size of longitudinal micro datasets used for the estimation of discrete time duration models, hsmlogit also provides the algebraic expressions of both first and second order derivatives that define the gradient vector and Hessian matrix, respectively, which significantly reduce time required to achieve model convergence [Gould et al., 2010].

The rest of the article estructures as follows: Section 2 describes the longitudinal database used to obtain estimation results; the econometric model and hsmlogit command syntax are explained, respectively, in Sections 3 and 4; Section 5 presents estimation results, and Section 6 shows the advantages of providing the algebraic expressions of both the gradient vector and Hessian matrix. Finally, Section 7 concludes.

\section{Database: The Continuous Sample of Working Histories}

I analyze a longitudinal sample of workers in the Spanish labor market that comes from the Continuous Sample of Working Histories database (CSWH, hereafter). The CSWH is a longitudinal database that provides the working histories records of more than one million people, who represent a $4 \%$ nonstratified random draw from a target population, composed of any person with a contribution relation with the Spanish Social Security Administration. It includes both wage workers and recipients of Social Security benefits, namely, unemployment benefits, disability, survivor pension and maternity leave. ${ }^{2}$

\footnotetext{
${ }^{1}$ An exception is the work presented in [Troncoso-Ponce, 2016], where a two-states multispells discrete time competing risks duration model with UH is estimated to analyze the effect of apprenticeship contracts in the Spanish labor market.

2 [García-Pérez, 2008], [Lapuerta, 2010], [Arranz and García-Serrano, 2011] and [Arranz, García-Serrano and Hernanz, 2013] contain a deep exposition about features of CSWH as well as all necessary techniques to perform a duration analysis using working lives information.
} 
The CSWH contains detailed information on each employment and unemployment episodes experienced by workers through their entire working histories. The information provided by the CSWH can be grouped into several categories: First, personal characteristics of workers (gender, age, nationality, educational level, residence place, and other personal characteristics). Second, job characteristics (type of labor contract, part-time coefficient, qualification level, and other job characteristics). Third, information on the employer (firm size, activity sector, and other firm characteristics). Furthermore, an important feature of the CSWH is that provides the beginning and termination dates of all employment and unemployment episodes, which takes special interest for duration analysis.

The estimation sample is composed of 48,246 low-educated and low-qualified young workers in the Spanish labor market for the period 2000-2014. The average age is 22.5 years-old, and $75.5 \%$ of them are males. The average number of employment episodes per worker is 8.9, lasting, on average, 7.13 months. Indeed, more than $25 \%$ of all employment episodes last 2 months or less, and only $5 \%$ last at least 24 months, which highlights the high turnover rate experienced by these workers. Multispell estimation sample has 1,316,611 observations. A describe output is shown below, describing the estimation sample's full varlist, as well as a summarize outuput to show the main descriptive statistics of the estimation sample's varlist. 


\section{Description of the estimation sample's varlist}

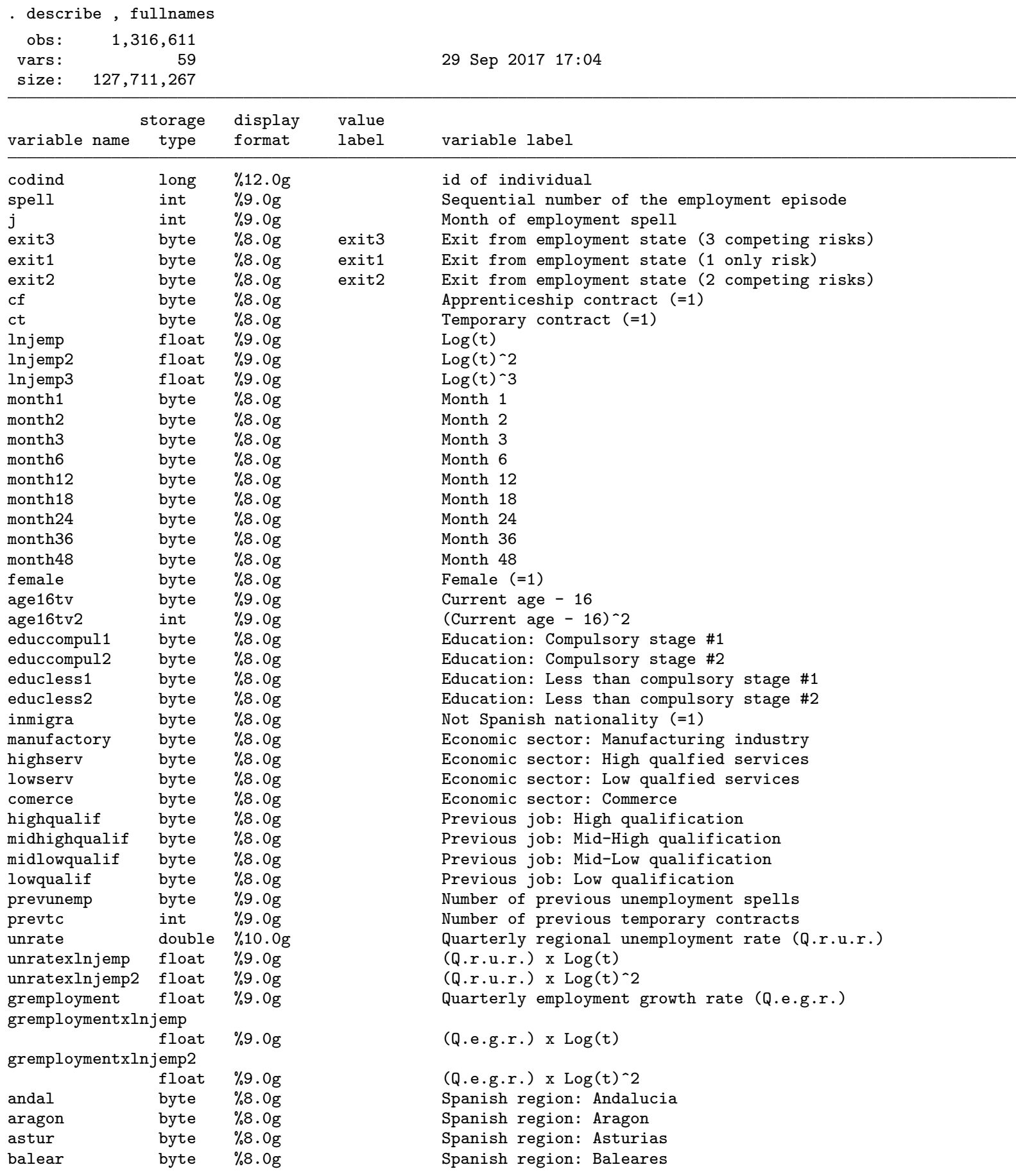



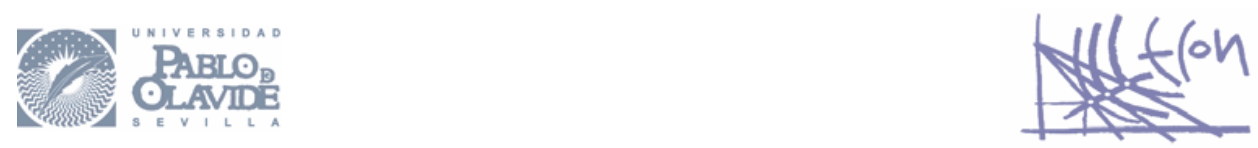

$\begin{array}{llll}\text { canar } & \text { byte } & \% 8.0 \mathrm{~g} & \text { Spanish region: Canarias } \\ \text { cantab } & \text { byte } & \% 8.0 \mathrm{~g} & \text { Spanish region: Cantabria } \\ \text { castman } & \text { byte } & \% 8.0 \mathrm{~g} & \text { Spanish region: Castilla La Mancha } \\ \text { castleon } & \text { byte } & \% 8.0 \mathrm{~g} & \text { Spanish region: Castilla Leon } \\ \text { valenc } & \text { byte } & \% 8.0 \mathrm{~g} & \text { Spanish region: Valencia } \\ \text { extrem } & \text { byte } & \% 8.0 \mathrm{~g} & \text { Spanish region: Extremadura } \\ \text { galic } & \text { byte } & \% 8.0 \mathrm{~g} & \text { Spanish region: Galicia } \\ \text { murcia } & \text { byte } & \% 8.0 \mathrm{~g} & \text { Spanish region: Murcia } \\ \text { navarr } & \text { byte } & \% 8.0 \mathrm{~g} & \text { Spanish region: Navarra } \\ \text { vasco } & \text { byte } & \% 8.0 \mathrm{~g} & \text { Spanish region: Pais Vasco } \\ \text { rioja } & \text { byte } & \% 8.0 \mathrm{~g} & \text { Spanish region: La Rioja }\end{array}$

Sorted by: codind spell j 


\section{Descriptive statistics of the estimation sample's varlist}

\begin{tabular}{|c|c|c|c|c|c|}
\hline Variable & $\mathrm{Obs}$ & Mean & Std. Dev. & Min & $\operatorname{Max}$ \\
\hline codind & $1,316,611$ & 3800765 & 2579758 & 1868 & $1.00 e+07$ \\
\hline spell & $1,316,611$ & 8.951002 & 13.46625 & 1 & 435 \\
\hline & $1,316,611$ & 7.132385 & 9.23605 & 1 & 108 \\
\hline exit3 & $1,316,611$ & .3740976 & .7186157 & 0 & 3 \\
\hline exit1 & $1,316,611$ & .2373564 & .4254626 & 0 & 1 \\
\hline exit2 & $1,316,611$ & .369709 & .7054998 & 0 & 2 \\
\hline$c f$ & $1,316,611$ & .16471 & .3709188 & 0 & 1 \\
\hline ct & $1,316,611$ & .83529 & .3709188 & 0 & 1 \\
\hline lnjemp & $1,316,611$ & 1.407723 & 1.039737 & 0 & 4.682131 \\
\hline lnjemp2 & $1,316,611$ & 3.062737 & 3.439172 & 0 & 21.92235 \\
\hline lnjemp3 & $1,316,611$ & 7.66514 & 11.91313 & 0 & 102.6433 \\
\hline month1 & $1,316,611$ & .2119381 & .4086814 & 0 & 1 \\
\hline month2 & $1,316,611$ & .1404713 & .3474754 & 0 & 1 \\
\hline month3 & $1,316,611$ & .1057419 & .3075072 & 0 & 1 \\
\hline month 6 & $1,316,611$ & .054834 & .227656 & 0 & 1 \\
\hline month12 & $1,316,611$ & .0209416 & .1431891 & 0 & 1 \\
\hline month18 & $1,316,611$ & .0090034 & .0944583 & 0 & 1 \\
\hline month24 & $1,316,611$ & .0052263 & .072104 & 0 & 1 \\
\hline month36 & $1,316,611$ & .0014818 & .0384661 & 0 & 1 \\
\hline month48 & $1,316,611$ & .0005301 & .0230189 & 0 & 1 \\
\hline female & $1,316,611$ & .2444549 & .4297637 & 0 & 1 \\
\hline age16tv & $1,316,611$ & 5.573653 & 3.642791 & 0 & 22 \\
\hline age16tv2 & $1,316,611$ & 44.33552 & 53.2066 & 0 & 484 \\
\hline educcompul1 & $1,316,611$ & .1649796 & .3711623 & 0 & 1 \\
\hline educcompul2 & $1,316,611$ & .4394009 & .4963143 & 0 & 1 \\
\hline educless1 & $1,316,611$ & .2096162 & .4070349 & 0 & 1 \\
\hline educless 2 & $1,316,611$ & .1860033 & .3891095 & 0 & 1 \\
\hline inmigra & $1,316,611$ & .1212887 & .3264626 & 0 & 1 \\
\hline manufactory & $1,316,611$ & .1599212 & .3665331 & 0 & 1 \\
\hline highserv & $1,316,611$ & .0580111 & .2337645 & 0 & 1 \\
\hline lowserv & $1,316,611$ & .1449327 & .3520331 & 0 & 1 \\
\hline comerce & $1,316,611$ & .1784703 & .3829083 & 0 & 1 \\
\hline highqualif & $1,316,611$ & .0061841 & .0783953 & 0 & 1 \\
\hline midhighqua f & $1,316,611$ & .0349579 & .1836734 & 0 & 1 \\
\hline midlowqualif & $1,316,611$ & .3149009 & .4644766 & 0 & 1 \\
\hline lowqualif & $1,316,611$ & .6439571 & .4788283 & 0 & 1 \\
\hline prevunemp & $1,316,611$ & 1.988224 & 2.428205 & 0 & 25 \\
\hline prevtc & $1,316,611$ & 5.621923 & 12.12324 & 0 & 431 \\
\hline unrate & $1,316,611$ & 11.85796 & 5.19547 & 3.9 & 36.87 \\
\hline unratexlnj $\sim p$ & $1,316,611$ & 17.4539 & 17.60828 & 0 & 169.4221 \\
\hline unratexlnj 2 & $1,316,611$ & 39.34931 & 58.8646 & 0 & 778.5148 \\
\hline gremployment & $1,316,611$ & 2.102568 & 3.801228 & -14.00105 & 10.99764 \\
\hline gremployme $\sim p$ & $1,316,611$ & 2.442792 & 7.083604 & -62.03608 & 38.71074 \\
\hline gremployme 2 & $1,316,611$ & 4.294824 & 19.12216 & -274.8705 & 142.1837 \\
\hline andal & $1,316,611$ & .2453321 & .4302841 & 0 & 1 \\
\hline aragon & $1,316,611$ & .0239395 & .1528608 & 0 & 1 \\
\hline
\end{tabular}




\begin{tabular}{r|rrrrr} 
astur & $1,316,611$ & .0198137 & .1393599 & 0 & 1 \\
balear & $1,316,611$ & .0305026 & .1719656 & 0 & 1 \\
canar & $1,316,611$ & .046025 & .2095393 & 0 & 1 \\
cantab & $1,316,611$ & .013935 & .1172214 & 0 & 1 \\
\hline castman & $1,316,611$ & .0572325 & .2322865 & 0 & 1 \\
castleon & $1,316,611$ & .0449579 & .2072117 & 0 & 1 \\
valenc & $1,316,611$ & .1079005 & .3102548 & 0 & 1 \\
extrem & $1,316,611$ & .0249443 & .1559556 & 0 & 1 \\
galic & $1,316,611$ & .0732874 & .2606078 & 0 & 1 \\
\hline murcia & $1,316,611$ & .0322449 & .1766499 & 0 & 1 \\
navarr & $1,316,611$ & .0085128 & .0918711 & 0 & 1 \\
vasco & $1,316,611$ & .0262386 & .1598441 & 0 & 1 \\
rioja & $1,316,611$ & .0053638 & .0730411 & 0 & 1
\end{tabular}

\section{Econometric model}

This Section briefly describes the main features of the econometric models that will be estimated in Section 5. The main goal of this kind of models is to analyze duration spent by a population in a specific state (in this example, employment state), as well as to analyze the set of factors, observable and specially unobservable, that affect time spent in that state (see [Lancaster, 1992], [Allison, 1982] and [Jenkins, 1995]).

Let's consider an individual beginning an employment episode at time $T=1$ (time $T$ is measured in month intervals). The worker is observed monthly during the employment episode until either he/she exits to another modeled state (such as, unemployment, or finding a new job), or the observation window ends (right censored observations). Employment duration is analyzed by estimating the hazard rate out of employment at each observed month. Depending on the number of exits (i.e. risks) modeled by the command's user, hsmlogit can estimate two different functional forms for the hazard rate.

Single-risk models use a Logit functional form to characterize the hazard rate, given by the following expression:

$$
h(t \mid x, \eta)=\frac{\exp (\lambda(t)+x \beta+\eta)}{1+\exp (\lambda(t)+x \beta+\eta)}
$$

And competing risks models use a Multinomial Logit functional form to characterize the hazard rates:

$$
h_{d}\left(t \mid x_{d}, \eta\right)=\frac{\exp \left(\lambda_{d}(t)+x_{d} \beta_{d}+\eta\right)}{1+\sum_{d=1}^{D} \exp \left(\lambda_{d}(t)+x_{d} \beta_{d}+\eta\right)}
$$

Assuming that $h=\sum_{d=1}^{D} h_{d}$, where $d=1, \ldots, D$ and $D=\{1,2,3\}$ depending on the total number of risks modeled by the command's user. 
As the two expressions above show, the hazard rate at month $T=t$ depends on time (months) spent in the current unemployment state (i.e. duration dependence), captured by $\lambda(t)$, as well as on a set of covariates summarized by $x$ vector, that may contain both time-fixed and time-varying covariates. Furthermore, the hazard rate also depends on an unobserved component given by $\eta$, that mesasures factors, such as job search effort, job networking, motivation, ability, etc, that are unobserved to the researcher and may affect the transition rate out of employment.

For the case of one-risk models, the contribution to the likelihood function of an individual $i$ is given by the following expression:

$$
L_{i}=\sum_{j=1}^{P} \pi_{j}\left\{\prod_{t=1}^{T_{i}} \frac{h\left(T=t \mid \lambda(t), x_{i t}, \eta_{j}\right)^{y_{i t}}}{\left(1-h\left(T=t \mid \lambda(t), x_{i t}, \eta_{j}\right)\right)^{\left(1-y_{i t}\right)}} S\left(T=t \mid \lambda(t), x_{i t}, \eta_{j}\right)^{\left(1-y_{i t}\right)}\right\}
$$

Where dependent variable $y_{i t}=\{0,1\}$ denotes a dummy variable that takes value 1 if worker $i$ exits out from employment at month $T=t$, and takes value zero otherwise. ${ }^{3}$ Expression given by $h\left(T=t \mid \lambda(t), x_{i t}, \eta_{j}\right)$ denotes the hazard rate observed at month $T=t$, and $S\left(T=t \mid \lambda(t), x_{i t}, \eta_{j}\right)$ denotes the survival rate observed at month $T=t$, that estimates the cummulative probability of being employed (from the month $T=1$ ) until the month $T=t$, and that is given by the following expression:

$$
S\left(T=t \mid \lambda(t), x_{i t}, \eta_{j}\right)=\prod_{s=1}^{t}\left(1-h\left(T=s \mid \lambda(s), x_{i s}, \eta_{j}\right)\right)
$$

As expressions 1 and 4 show, the hazard rate observed at month $T=t$ is conditional on the duration dependence $\lambda(t)$ and on the set of covariates $x_{i t}$. And the survival rate at month $T=t$ is conditional on $\lambda(s)$ and on the set of covariates $x_{i s}$, observed at months $s=1,2, \ldots, t$. Both the hazard and the survival rates also depend on belonging to the type of employed workers with unobserved characteristics given by $\eta_{j} \cdot{ }^{4}$

The total likelihood function of single-risk models is given by:

$L=\prod_{i=1}^{N} \sum_{j=1}^{P} \pi_{j}\left\{\prod_{t=1}^{T_{i}} \frac{h\left(T=t \mid \lambda(t), x_{i t}, \eta_{j}\right)^{y_{i t}}}{\left(1-h\left(T=t \mid \lambda(t), x_{i t}, \eta_{j}\right)\right)^{\left(1-y_{i t}\right)}} S\left(T=t \mid \lambda(t), x_{i t}, \eta_{j}\right)^{\left(1-y_{i t}\right)}\right\}$

hsmlogit command maximizes, using d2 ml method, the natural logarithm of $L$ to estimate the model parameters.

\footnotetext{
${ }^{3}$ Dependent variable $y_{i t}$ refers to dead (deadvar) of hsmlogit command.

${ }^{4}$ It is assumed that unobserved characteristics do not vary with time and are not correlated to the rest of explanatory variables included in the specification of the hazard rate.
} 
For the case of competing risks models, the contribution to the likelihood function of an individual $i$ is given by the following expression:

$L_{i}=\sum_{j=1}^{P} \pi_{j}\left\{\prod_{t=1}^{T_{i}} \prod_{d=1}^{D}\left\{h_{d}\left(T_{d}=t \mid \lambda_{d}(t), x_{i t}^{d}, \eta_{j}\right)^{y_{i t}^{d}}\right\} S\left(T=t-1 \mid \lambda(t), x_{i t}, \eta_{j}\right)^{\left(1-\sum_{d=1}^{D} y_{i t}^{d}\right)}\right\}$

Where $h_{d}\left(T_{d}=t \mid \lambda_{d}(t), x_{i t}^{d}, \eta_{j}\right)$ denotes the hazard rate for the especific risk $d=1, \ldots, D$ observed at month $T=t$, conditional on the duration dependence $\lambda_{d}(t)$, on the set of covariates $x_{i t}^{d}$, and on belonging to the type of employed workers with unobserved characteristics given by $\eta_{j}$. Dependent variable $y_{i t}^{d}=\{0,1\}$, for $d=1, \ldots, D$, denotes a dummy variable that takes value 1 if worker $i$ exits out from employment towards the destination $d$ at month $T_{d}=t$, and takes value zero otherwise.

Unlike single-risk models, the survival function for competing risks takes into account the all possible risks faced by the individual at month $T=t$, and therefore takes the following expression:

$$
S\left(T=t-1 \mid \lambda(t-1), x_{i t-1}, \eta_{j}\right)=\prod_{s=1}^{t-1}\left(1-\sum_{d=1}^{D} h_{d}\left(T_{d}=s \mid \lambda_{d}(s), x_{i s}^{d}, \eta_{j}\right)\right)
$$

Similarly to single-risk models, the total likelihood function for competing risks is given by:

$L=\prod_{i=1}^{N} \sum_{j=1}^{P} \pi_{j}\left\{\prod_{t=1}^{T_{i}} \prod_{d=1}^{D}\left\{h_{d}\left(T_{d}=t \mid \lambda_{d}(t), x_{i t}^{d}, \eta_{j}\right)^{y_{i t}^{d}}\right\} S\left(T=t-1 \mid \lambda(t), x_{i t}, \eta_{j}\right)^{\left(1-\sum_{d=1}^{D} y_{i t}^{d}\right)}\right\}$

And likewise single-risk models, hsmlogit command maximizes, also using d2 $\mathrm{ml}$ method, the natural logarithm of $L$ to estimate the model parameters for competing risks models.

\subsection{The non-parametric identification of the UH distribution}

Regarding the estimation of UH distribution, we assume the existence of unobserved factors affecting hazard rates, that if are ignored, may lead to spurious duration dependence, captured by $\lambda(t)$ ([Van Den Berg, 2001]). A well known method to capture the effect of $\mathrm{UH}$ on the hazard rates is the proposed by [Heckman and Singer, 1984], by which the UH components are captured without imposing any parametric distribution function for the identification of UH distribution, but as a discrete mixture of several types of individuals with different values of UH components. Thus, it is assumed the presence of different types of workers who characterize themselves by having different levels of unobserved 
variables (such as, ability, cognitive and non cognitive skills, social and networking capabilities, etc.), captured by the set of parameters $\eta=\left\{\eta_{1}, \eta_{2}, \ldots, \eta_{P}\right\}$, that are estimated as regression's constant terms. ${ }^{5}$ For each Type of worker $j$, characterized by $\eta_{j}$, an associated probability of being observed in the data, given by $\pi=\left\{\pi_{1}, \pi_{2}, \ldots, \pi_{P}\right\}$, is also estimated jointly with the rest of the model parameters. Finally, the non-parametric discrete UH distribution is the result of the combination of these Types of workers, whose different values of UH are given by the vector $\eta=\left\{\eta_{1}, \eta_{2}, \ldots, \eta_{P}\right\}$ and by their associated probabilities $\pi=\left\{\pi_{1}, \pi_{2}, \ldots, \pi_{P}\right\}$, are estimated jointly with the rest of the model parameters.

Furthermore, likewise hshaz2 command, when more than two mass-points are especified by the command's user, hsmlogit also properly estimates masspoints probabilities using a Multinomial Logit function, rather than a Logit one, to compute the values of $\left(\pi_{1}, \pi_{2}, \ldots, \pi_{P}\right)$ (see [Troncoso-Ponce, 2017]). For example, when the UH distribution is characterized by five points of support, the mass probabilty parameteres computed by hsmlogit take the following expression: $\pi_{j}=\frac{e^{p_{j}}}{1+\sum_{l=2}^{5} e^{p_{l}}}$, for $j=2, \ldots, 5$, and $\pi_{1}=1-\sum_{l=2}^{5} \pi_{l}$. And for the computation of the standard errors of mass probability parameters, hsmlogit also provides to _diparm() command the algebraric expressions of the first order derivatives of each $\pi_{j}=\frac{e^{p_{j}}}{1+\sum_{l=2}^{L} e^{p_{l}}}$, for each $j=1,2, \ldots, P$, with respect to each $p_{l}$, with $l=2,3, \ldots, P$.

\section{Command syntax}

The hsmlogit's command syntax follows the same design that hshaz and hshaz2's. The only difference between hsmlogit's command syntax and hshaz2's is added by dead(deadvar) option. Unlike hshaz2, the dead(deadvar) option of hsmlogit command identifies whether the dependent variable typed by the command user in the dead(deadvar) option takes one, two or three risks. Therefore, hsmlogit, depending on the number of the values taken by the dependent variable, estimates, respectively, a single, a two, or a three competing risks duration model. The rest options of hsmlogit's command syntax are the same that hshaz2's (see [Troncoso-Ponce, 2017]).

The hsmlogit command syntax is:

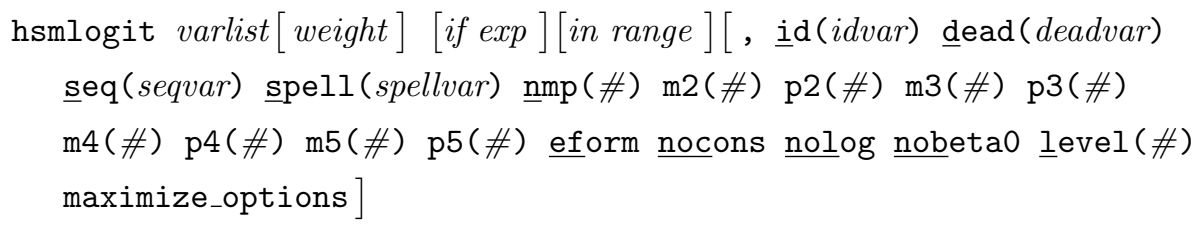

\footnotetext{
${ }^{5}$ As previously mentioned, hsmlogit allows for the estimation of a maximum of five points of support (ie. Types of workers) for the identification of the UH distribution.
} 


\section{Estimation results}

This Section shows results from the estimation of three duration models, each of them depends on the number of exits modeled. The first model, presented below in the first estimation output (Single risk model with UH using hsmlogit), simply estimates the transition rate out of employment without differentiating the destination state. The second one, shown below in the second estimation output (Two competing risks model with UH using hsmlogit), estimates a two risks duration model, by which the two modeled risks are: i) exiting to unemployment; and ii) a job-to-job transition to another employment. Finally, the third model, shown below in the third estimation output (Three competing risks model with UH using hsmlogit), allows for distinguishing the type of labor contract of the new employment found in the job-to-job transition. Specifically, the model differs between finding a fixed-term contract, and an open-ended one. Therefore, these three competing risks are: i) exiting to unemployment; ii) finding a fixed-term contract; and iii) finding an open-ended contract.

As mentioned in Section 3, the functional form of the hazard rate estimated in the first model is given by a Logit function, whereas the hazard rates of the second and third models are given by Multinomial Logit functions with two a three competing risks, respectively. The mentioned three tables with the estimation output show estimation results of fitting multispells duration models with two mass-points of unobserved heterogeneity. ${ }^{6}$

For the three estimated models, the set of covariates included in the specification of the hazard rates controls for the effect of: i) personal characteristics of the employed workers, such as, gender, age (age16tv) and squared age (age16tv2), ${ }^{7}$ nationality, ${ }^{8}$ and educational level ${ }^{9}$; ii) business cycle effects, by including the quarterly unemployment rate (unrate) and the product of the unemployment rate with the natural logarithm of the current employment spell (unratexlnjemp), and its squared (unratexlnjemp2); iv) a set of dummy variables that identify the Spanish regions (andal-rioja) to capture regional effects. Additionally to the duration dependence specification (using a three order polynomial of the natural logarithm of the duration of current employment spell), three dummy variables are included to identify months $6,12,18$ and 24. These dummy variables are included to capture exit peaks related to the duration of temporary contracts in the Spanish labor market. Finally, to capture the effect of holding an apprenticeship contract on the employment exit

\footnotetext{
${ }^{6}$ All estimation results, with and without UH, shown in this article are available to the interested reader upon request.

${ }^{7}$ Age covariates measure the difference between the current age (time-varying age) with respect to the legal working age in the Spanish labor market, 16 years old.

${ }^{8}$ Nationality effect is captured using a dummy variable, called inmigra, that takes value one if the employed worker is not Spanish, and zero otherwise.

${ }^{9}$ The effect of educational level is captured by including two dummy variables: educcompul1 and educcompul2. Dummy variable educcompul1 (educcompul2) takes value one whether the worker has a primary (secondary) compulsory education degree, and takes zero otherwise.
} 
rate, the dummy variable (cf) takes value one whether the worker is holding an apprenticeship contract, and takes value zero whether the worker has another type of temporary contract different from the apprenticeship one. ${ }^{10}$ The regression coefficients not shown in the estimation output tables are omitted due to space reasons, and are available to the interested reader upon request.

\footnotetext{
${ }^{10}$ Hence, the regressions' constant term contains male native employed workers holding a temporary contract in the Spanish regions Madrid and Catalonia, with less than primary compulsory education.
} 


\section{Single risk model with UH using hsmlogit}

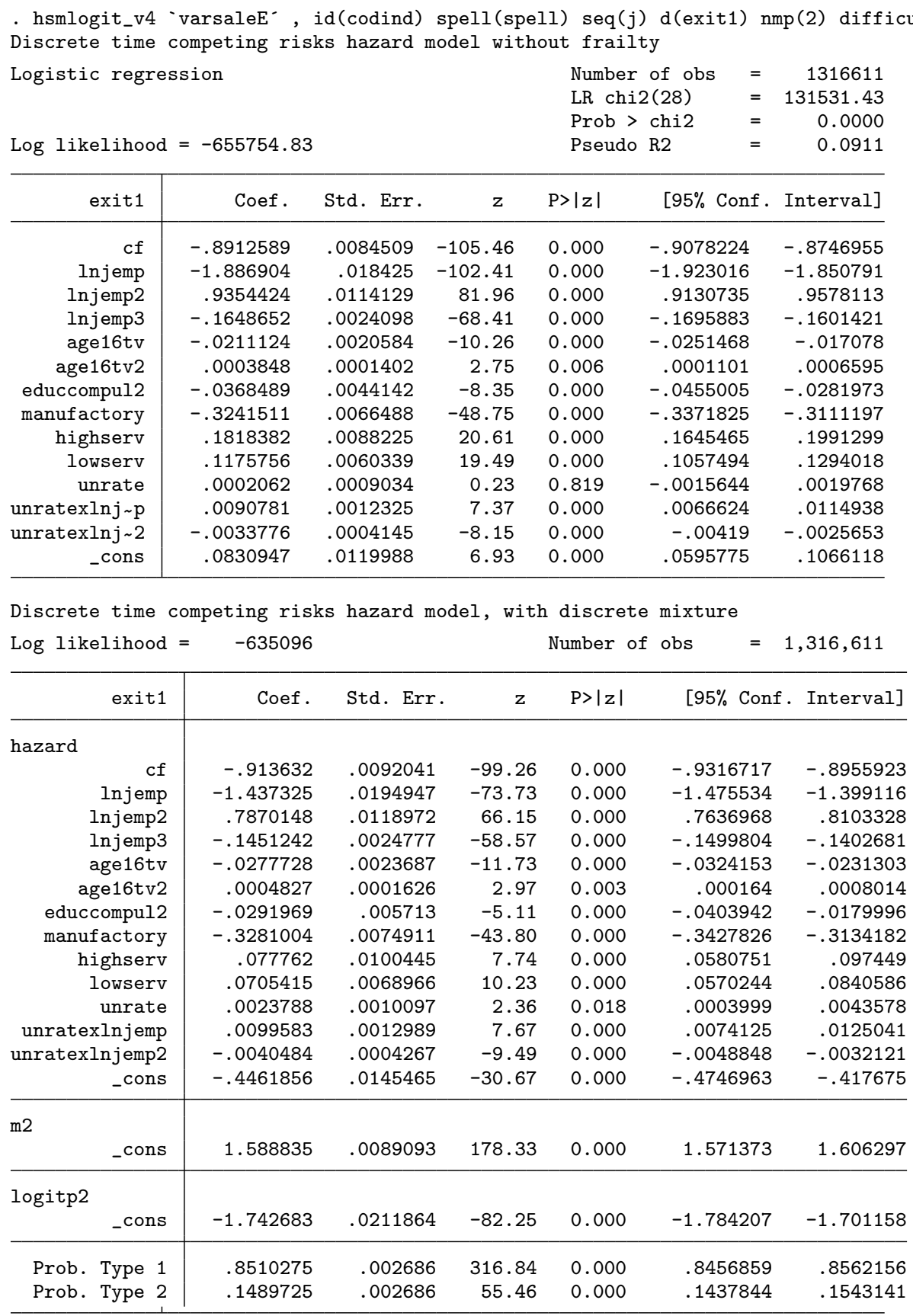

Note: $m 1=0$ 
Two competing risks model with UH using hsmlogit

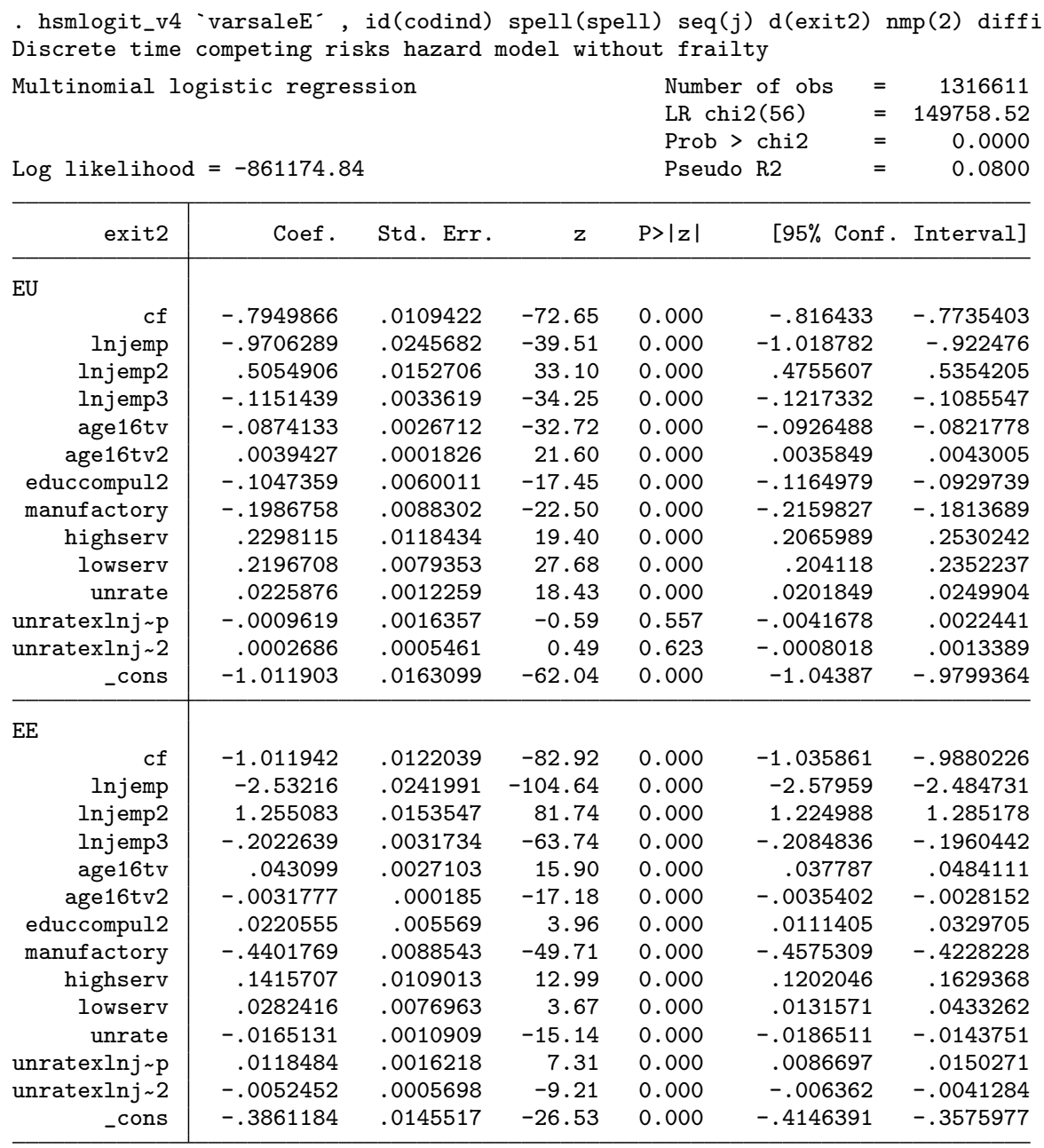

(exit2==no exit is the base outcome) 
Discrete time competing risks hazard model, with discrete mixture Log likelihood $=-840603.57$

Number of obs

$=1,316,611$

\begin{tabular}{|c|c|c|c|c|c|c|}
\hline exit2 & Coef. & Std. Err. & z & $P>|z|$ & {$[95 \%$ Conf. } & Interval] \\
\hline \multicolumn{7}{|l|}{ hazard1 } \\
\hline cf & -.8244588 & .0115585 & -71.33 & 0.000 & -.8471131 & -.8018045 \\
\hline Injemp & -.5313624 & .0253333 & -20.97 & 0.000 & -.5810148 & -.4817099 \\
\hline Injemp2 & .3610352 & .01561 & 23.13 & 0.000 & .3304402 & .3916302 \\
\hline Injemp3 & -.0957306 & .0034033 & -28.13 & 0.000 & -.102401 & -.0890603 \\
\hline age16tv & -.0934056 & .0028976 & -32.24 & 0.000 & -.0990848 & -.0877263 \\
\hline age16tv2 & .0039949 & .0001992 & 20.06 & 0.000 & .0036046 & .0043852 \\
\hline educcompul2 & -.0968852 & .0069518 & -13.94 & 0.000 & -.1105105 & -.08326 \\
\hline manufactory & -.211835 & .0094664 & -22.38 & 0.000 & -.2303887 & -.1932812 \\
\hline highserv & .1350418 & .0127147 & 10.62 & 0.000 & .1101215 & .1599621 \\
\hline lowserv & .1745412 & .0085626 & 20.38 & 0.000 & .1577589 & .1913235 \\
\hline unrate & .024601 & .0013045 & 18.86 & 0.000 & .0220443 & .0271577 \\
\hline unratexlnjemp & .0004602 & .0016838 & 0.27 & 0.785 & -.0028401 & .0037605 \\
\hline unratexlnjemp2 & -.0005451 & .0005548 & -0.98 & 0.326 & -.0016324 & .0005422 \\
\hline _cons & -1.540267 & .0182031 & -84.62 & 0.000 & -1.575944 & -1.504589 \\
\hline \multicolumn{7}{|l|}{ hazard2 } \\
\hline $\operatorname{cf}$ & -1.02528 & .0127572 & -80.37 & 0.000 & -1.050284 & -1.000277 \\
\hline Injemp & -2.078786 & .0250507 & -82.98 & 0.000 & -2.127885 & -2.029688 \\
\hline Injemp2 & 1.107497 & .015722 & 70.44 & 0.000 & 1.076683 & 1.138312 \\
\hline Injemp3 & -.1831092 & .0032193 & -56.88 & 0.000 & -.1894189 & -.1767995 \\
\hline age16tv & .038407 & .0029839 & 12.87 & 0.000 & .0325588 & .0442553 \\
\hline age16tv2 & -.0031854 & .000205 & -15.54 & 0.000 & -.0035871 & -.0027836 \\
\hline educcompul2 & .0336721 & .0067271 & 5.01 & 0.000 & .0204872 & .0468571 \\
\hline manufactory & -.4384897 & .0095412 & -45.96 & 0.000 & -.45719 & -.4197893 \\
\hline highserv & .0295985 & .0119948 & 2.47 & 0.014 & .006089 & .0531079 \\
\hline lowserv & -.0230854 & .0084529 & -2.73 & 0.006 & -.0396528 & -.0065181 \\
\hline unrate & -.0144479 & .0011802 & -12.24 & 0.000 & -.0167611 & -.0121346 \\
\hline unratexlnjemp & .0123513 & .0016725 & 7.38 & 0.000 & .0090732 & .0156294 \\
\hline unratexlnjemp2 & -.0058043 & .0005786 & -10.03 & 0.000 & -.0069384 & -.0046703 \\
\hline _cons & -.9270718 & .0167796 & -55.25 & 0.000 & -.9599592 & -.8941844 \\
\hline \multicolumn{7}{|l|}{$\mathrm{m} 2$} \\
\hline -cons & 1.584087 & .0088521 & 178.95 & 0.000 & 1.566737 & 1.601437 \\
\hline \multicolumn{7}{|l|}{ logitp2 } \\
\hline _cons & -1.730903 & .0210766 & -82.12 & 0.000 & -1.772212 & -1.689593 \\
\hline Prob. Type 1 & .8495279 & .0026942 & 315.31 & 0.000 & .8441707 & .8547326 \\
\hline Prob. Type 2 & .1504721 & .0026942 & 55.85 & 0.000 & .1452674 & .1558293 \\
\hline
\end{tabular}

Note: $\mathrm{m} 1=0$ 
Three competing risks with $\mathrm{UH}$ using hsmlogit

\begin{tabular}{|c|c|c|c|c|c|c|}
\hline \multicolumn{4}{|c|}{ Multinomial logistic regression } & \multicolumn{2}{|c|}{$\begin{array}{l}\text { Number of obs } \\
\text { LR chi2 }(84) \\
\text { Prob > chi2 } \\
\text { Pseudo R2 }\end{array}$} & $\begin{array}{lr}= & 1316611 \\
= & 160654.70 \\
= & 0.0000 \\
= & 0.0836\end{array}$ \\
\hline exit3 & Coef. & Std. Err. & $z$ & $P>|z|$ & {$[95 \%$ Conf. } & Interval] \\
\hline \multicolumn{7}{|l|}{$\mathrm{EU}$} \\
\hline$c f$ & -.7986611 & .0109406 & -73.00 & 0.000 & -.8201043 & -.7772179 \\
\hline lnjemp & -.9709934 & .0245729 & -39.51 & 0.000 & -1.019155 & -.9228314 \\
\hline lnjemp2 & .5069499 & .0152775 & 33.18 & 0.000 & .4770066 & .5368933 \\
\hline Injemp3 & -.1157149 & .0033656 & -34.38 & 0.000 & -.1223114 & -.1091185 \\
\hline age16tv & -.0881035 & .0026718 & -32.98 & 0.000 & -.0933401 & -.0828668 \\
\hline age16tv2 & .0039923 & .0001826 & 21.86 & 0.000 & .0036344 & .0043502 \\
\hline educcompul2 & -.105202 & .0060017 & -17.53 & 0.000 & -.1169652 & -.0934388 \\
\hline manufactory & -.2006661 & .0088305 & -22.72 & 0.000 & -.2179736 & -.1833587 \\
\hline highserv & .2296968 & .0118453 & 19.39 & 0.000 & .2064804 & .2529132 \\
\hline lowserv & .2180955 & .0079363 & 27.48 & 0.000 & .2025406 & .2336503 \\
\hline unrate & .022578 & .0012261 & 18.41 & 0.000 & .0201749 & .0249811 \\
\hline unratexlnj p & -.0011119 & .0016364 & -0.68 & 0.497 & -.0043191 & .0020953 \\
\hline _cons & -1.009577 & .0163131 & -61.89 & 0.000 & -1.04155 & -.9776039 \\
\hline \multicolumn{7}{|l|}{ ET } \\
\hline$c f$ & -1.214204 & .0134696 & -90.14 & 0.000 & -1.240604 & -1.187804 \\
\hline lnjemp & -2.566013 & .0252271 & -101.72 & 0.000 & -2.615457 & -2.516569 \\
\hline lnjemp2 & 1.310668 & .0165322 & 79.28 & 0.000 & 1.278266 & 1.343071 \\
\hline lnjemp3 & -.2269325 & .0035308 & -64.27 & 0.000 & -.2338528 & -.2200123 \\
\hline age16tv & .0348604 & .0027452 & 12.70 & 0.000 & .0294799 & .0402409 \\
\hline age16tv2 & -.002567 & .0001871 & -13.72 & 0.000 & -.0029338 & -.0022002 \\
\hline educcompul2 & .0164089 & .0056687 & 2.89 & 0.004 & .0052985 & .0275193 \\
\hline manufactory & -.4715925 & .0091037 & -51.80 & 0.000 & -.4894354 & -.4537496 \\
\hline highserv & .1380367 & .0110533 & 12.49 & 0.000 & .1163726 & .1597009 \\
\hline lowserv & .0082154 & .0078295 & 1.05 & 0.294 & -.0071302 & .023561 \\
\hline unrate & -.0164156 & .001101 & -14.91 & 0.000 & -.0185736 & -.0142576 \\
\hline unratexlnj p & .0097402 & .0016896 & 5.76 & 0.000 & .0064288 & .0130517 \\
\hline _cons & -.3760623 & .0146951 & -25.59 & 0.000 & -.4048642 & -.3472603 \\
\hline \multicolumn{7}{|l|}{ EP } \\
\hline$c f$ & .7109967 & .035604 & 19.97 & 0.000 & .6412142 & .7807791 \\
\hline emp & -2.083359 & .1148221 & -18.14 & 0.000 & -2.308406 & -1.858312 \\
\hline lnjemp2 & 1.077243 & .056833 & 18.95 & 0.000 & .9658519 & 1.188633 \\
\hline lnjemp3 & -.1234547 & .0099939 & -12.35 & 0.000 & -.1430423 & -.1038671 \\
\hline age16tv & .2424454 & .0156192 & 15.52 & 0.000 & .2118325 & .2730584 \\
\hline age16tv2 & -.0191269 & .0011496 & -16.64 & 0.000 & -.0213801 & -.0168737 \\
\hline educcompul2 & .151788 & .0268159 & 5.66 & 0.000 & .0992299 & .2043462 \\
\hline manufactory & .149392 & .0355004 & 4.21 & 0.000 & .0798125 & .2189714 \\
\hline highserv & .2252933 & .057029 & 3.95 & 0.000 & .1135184 & .3370681 \\
\hline lowserv & .5072968 & .0360027 & 14.09 & 0.000 & .4367328 & .5778609 \\
\hline unrate & -.0802567 & .0089966 & -8.92 & 0.000 & -.0978896 & -.0626237 \\
\hline atexlnj p & .0610449 & .0089799 & 6.80 & 0.000 & .0434446 & .0786453 \\
\hline _cons & -4.808289 & .1012222 & -47.50 & 0.000 & -5.006681 & -4.609897 \\
\hline
\end{tabular}

(exit3==no exit is the base outcome) 
Discrete time competing risks hazard model, with discrete mixture Log likelihood $=-860570.7$

Number of obs

$=1,316,611$

\begin{tabular}{|c|c|c|c|c|c|c|}
\hline exit3 & Coef. & Std. Err. & $z$ & $P>|z|$ & {$[95 \%$ Conf. } & Interval] \\
\hline \multicolumn{7}{|l|}{ hazard1 } \\
\hline$c f$ & -.8317648 & .0115702 & -71.89 & 0.000 & -.8544421 & -.8090876 \\
\hline Injemp & -.5323972 & .0253395 & -21.01 & 0.000 & -.5820617 & -.4827327 \\
\hline lnjemp2 & .3637062 & .0156171 & 23.29 & 0.000 & .3330973 & .3943152 \\
\hline lnjemp3 & -.0965266 & .0034067 & -28.33 & 0.000 & -.1032035 & -.0898496 \\
\hline age16tv & -.0946958 & .0028946 & -32.71 & 0.000 & -.1003691 & -.0890224 \\
\hline age16tv2 & .0041084 & .0001986 & 20.68 & 0.000 & .003719 & .0044977 \\
\hline educcompul2 & -.098385 & .0069564 & -14.14 & 0.000 & -.1120192 & -.0847508 \\
\hline manufactory & -.2151223 & .0094659 & -22.73 & 0.000 & -.2336751 & -.1965695 \\
\hline highserv & .1342664 & .0127151 & 10.56 & 0.000 & .1093452 & .1591875 \\
\hline lowserv & .1714203 & .0085664 & 20.01 & 0.000 & .1546305 & .1882101 \\
\hline unrate & .0246167 & .0013044 & 18.87 & 0.000 & .02206 & .0271733 \\
\hline unratexlnjemp & .0002379 & .0016847 & 0.14 & 0.888 & -.003064 & .0035398 \\
\hline _cons & -1.537957 & .0182095 & -84.46 & 0.000 & -1.573647 & -1.502267 \\
\hline \multicolumn{7}{|l|}{ hazard2 } \\
\hline$c f$ & -1.230282 & .0139993 & -87.88 & 0.000 & -1.25772 & -1.202843 \\
\hline lnjemp & -2.109857 & .0260808 & -80.90 & 0.000 & -2.160975 & -2.05874 \\
\hline lnjemp2 & 1.161366 & .0169049 & 68.70 & 0.000 & 1.128233 & 1.194499 \\
\hline lnjemp3 & -.2072636 & .0035771 & -57.94 & 0.000 & -.2142745 & -.2002527 \\
\hline age16tv & .0294043 & .0030183 & 9.74 & 0.000 & .0234885 & .0353201 \\
\hline age16tv2 & -.002497 & .000207 & -12.06 & 0.000 & -.0029027 & -.0020913 \\
\hline educcompul2 & .0270498 & .0068402 & 3.95 & 0.000 & .0136433 & .0404563 \\
\hline manufactory & -.4710222 & .0097941 & -48.09 & 0.000 & -.4902183 & -.4518261 \\
\hline highserv & .023543 & .0121529 & 1.94 & 0.053 & -.0002762 & .0473622 \\
\hline lowserv & -.0459738 & .008593 & -5.35 & 0.000 & -.0628157 & -.0291318 \\
\hline unrate & -.0143704 & .0011898 & -12.08 & 0.000 & -.0167023 & -.0120384 \\
\hline unratexlnjemp & .0101926 & .0017401 & 5.86 & 0.000 & .006782 & .0136031 \\
\hline _cons & -.9171136 & .0169239 & -54.19 & 0.000 & -.9502838 & -.8839434 \\
\hline \multicolumn{7}{|l|}{ hazard3 } \\
\hline$c f$ & .6758236 & .0358259 & 18.86 & 0.000 & .6056062 & .7460411 \\
\hline lnjemp & -1.679314 & .1147489 & -14.63 & 0.000 & -1.904217 & -1.45441 \\
\hline Injemp2 & .9649278 & .0568303 & 16.98 & 0.000 & .8535425 & 1.076313 \\
\hline lnjemp3 & -.1111428 & .0099834 & -11.13 & 0.000 & -.13071 & -.0915757 \\
\hline age16tv & .2357879 & .0156333 & 15.08 & 0.000 & .2051473 & .2664286 \\
\hline age16tv2 & -.0190263 & .0011489 & -16.56 & 0.000 & -.0212781 & -.0167745 \\
\hline educcompul2 & .1549394 & .0269799 & 5.74 & 0.000 & .1020597 & .2078191 \\
\hline manufactory & .134427 & .035673 & 3.77 & 0.000 & .0645092 & .2043449 \\
\hline highserv & .1660599 & .0571961 & 2.90 & 0.004 & .0539576 & .2781622 \\
\hline lowserv & .4844141 & .0361505 & 13.40 & 0.000 & .4135604 & .5552679 \\
\hline unrate & -.0763687 & .0089703 & -8.51 & 0.000 & -.0939502 & -.0587873 \\
\hline unratexlnjemp & .0608414 & .0089472 & 6.80 & 0.000 & .0433051 & .0783776 \\
\hline _cons & -5.338236 & .101233 & -52.73 & 0.000 & -5.536649 & -5.139823 \\
\hline \multicolumn{7}{|l|}{$\mathrm{m} 2$} \\
\hline _cons & 1.583831 & .0088365 & 179.24 & 0.000 & 1.566512 & 1.60115 \\
\hline \multicolumn{7}{|l|}{ logitp2 } \\
\hline _cons & -1.725456 & .0210304 & -82.05 & 0.000 & -1.766674 & -1.684237 \\
\hline Prob. Type 1 & .8488302 & .0026986 & 314.55 & 0.000 & .8434647 & .8540436 \\
\hline Prob. Type 2 & .1511698 & .0026986 & 56.02 & 0.000 & .1459564 & .1565353 \\
\hline
\end{tabular}


Note: $m 1=0$

The estimation exercise shown in this Section is addressed only to highlight the importance of allowing for modelling more than one single risk in a duration model that also takes into account the presence of UH. For that reason, analogously to [Troncoso-Ponce, 2017], the main purpose of these regressions is not intended to address a rigorous regression analysis to properly estimate the effect of a set of covariates on the probability of exiting out of employment. Therefore, in this Section, comments on detailed estimation results will be focused mainly on the impact of holding an apprenticeship contract (captured by the covariate $\mathrm{cf}$ in the three estimation outputs presented above) when we allow for modelling more than one single risk.

The single risk duration model estimates a statistically significant negative effect $(-0.9136)$ of holding an apprenticeship contract on the probability of exiting out from the employment state, which may suggest that apprenticeship contracts last longer (ie. seem to be more stable) than regular fixed-term contracts. And when we allow for modelling two competing risks (exiting to unemployment, or a job-to-job transition to another job), the effect of apprenticeship contracts remain negative and statistically significant on both the two risks modeled: exiting to exit to unemployment $(-0.8244)$, and a direct transition to another job $(-1.0252)$.

However, interestingly, the estimated effect of apprenticeship contracts turns positive when we allow for modelling the job-to-job transition separately in two different, and mutually exclusive, destinations: i) a direct transition to a fixedterm contract; and i) a direct transition to an open-ended contract. As the third estimation output shows, apprenticeship contracts increase the probability of experiencing a job-to-job transition towards an open-ended contract (0.7109). The main reason of observing this possitive effect is the role played by public financial incentives addressed to the conversion of apprenticeship contracts into open-ended ones. Apprenticeship contracts in Spain benefit from public subsidies for the conversion into open-ended contracts. These subsidies mainly consist of a significant reduction in Social Security contributions paid by the employer during a maximun period of three years, from the starting date of conversion of the apprenticeship contract into an open-ended one. The main goal of these financial incentives is to favour employment stability, and to foster the accumulation of employment experience of apprentices by allowing them to put in practice the work-specific skills acquired during the apprenticeship period. Thus, the possitive coefficient found (0.7109) may be capturing the effect of these public financial incentives provided by Spanish policy makers addressed to the conversion of apprenticeship contracts into open-ended ones.

An axhaustive analysis of the apprenticeship contracts in the Spanish labor market is presented in [Troncoso-Ponce, 2016] and [Jansen and Troncoso-Ponce, 2017]. The first one estimates a multispell and multistate competing risks duration 
Table 1: Interpretation of UH coefficients (three competing risks model)

\begin{tabular}{lcccc}
\hline \hline & Prob. & Emp. to Unemp. & Emp. to Fixed-term & Emp. to Open-ended \\
\hline Type I & $84.88 \%$ & -1.537957 & -0.9171136 & -5.338236 \\
Type II & $15.12 \%$ & $0.045874^{a}$ & $0.6667174^{b}$ & $-3.754405^{c}$ \\
\hline \hline \multicolumn{4}{l}{$(=-1.537957+1.583831)^{b}(=-0.9171136+1.583831)^{c}(=-5.338236+1.583831)$}
\end{tabular}

model with UH especific to both each state and to each destination state, as well as a selection equation that estimates the transition rates to the entry into the labor market holding three different types of labor contract: an apprenticeship contract, a fixed-term contract, and an open-ended contract. The second, and more recent, work also estimates a multispell and multistate competing risks duration model with $\mathrm{UH}$, but the selection equation consists of an initial conditions equation, rather than a transition rate equation, that controls for the effect of a set of observable covariates on the probability of having an apprenticeship contract just in the first employment spell of the individual's working life. Moreover, the empirical strategy followed in this work allows us to disentangle two types of effect: an instant effect, and a subsequent effect of apprenticeship contracts on the employment and unemployment transition rates.

\subsection{Some insights on the interpretation of UH coefficients}

Regarding the estimation and interpretation of UH coefficients, as we assume that $\eta_{1}$ is set to zero, ${ }^{11}$ the estimated regression's constant terms $(-1.537957$, -0.9171136 and -5.338236 , for the exit to unemployment, to a fixed-term, and to an open-ended contract, respectively) capture the UH component specific to Type I workers, whereas $\eta_{2}$ captures the unobserved differential effect of Type II workers with respect to Type I workers. Therefore, the estimated value of UH component specific to Type II workers are the result of the sum of the regression's constant terms and the estimated coefficient value of $\eta_{2}$.

Table 1 shows the estimated coefficients of the UH components of Type I and Type II workers from the estimation results of the three competing risks model. The estimation of the non-parametric UH distribution, characterized by the presence of two types of workers (two points of support), captures Type I and Type II workers who represent, respectively, $84.88 \%$ and $15.12 \%$ of the estimation sample. As Table 1 shows, Type II workers have unobserved characteristics that positively correlate to the employment hazard rates, which implies that Type II workers face employment transition rates (towards all the three

\footnotetext{
${ }^{11}$ It explains the footnote shown at the estimation output tables with the message "Note: $\mathrm{m} 1=0$ ", where $\mathrm{m} 1$ denotes UH component given by $\eta_{1}$. See also [Troncoso-Ponce, 2017] and hshaz command's official Stata helpfile.
} 
modeled risks) higher than Type I workers'.

In conclusion, the estimation of not only a single or a two competing risks, but a three competing risks duration model has allowed for capturing a positive and statistically significant effect of apprenticeship contracts on the probability of transiting directly (via job-to-job) to an open-ended contract, that otherwise would have remained hidden to the empirical researcher if only one risk, or even two, would have been estimated. Furthermore, given the relevance of UH, and its non parametric identification, in discrete time duration models with multispell observations (see, for example, [Gaure, Roed and Zhang, 2007] and [Abbring and Van den Berg, 2004]), the new Stata command hsmlogit takes especial relevance, as allows for the estimation of discrete time competing risks duration models with $\mathrm{UH}$.

\section{The advantages of using $\mathrm{ml} \mathrm{d} 2$ method}

As mentioned in Section 1, hsmlogit provides the algebraic expressions of both the gradient vector and Hessian matrix, allowing for using d2 ml method to achieve the model convergence. An important advantage of programming the Hessian matrix is that allows applied researchers to deal with large longitudinal microdata sets (see for example [Troncoso-Ponce, 2017]). To show the savyings in estimation time, this Section presents time required to estimate multispell both single and competing risks duration models (with 2, 3 and 4 mass-points) using d0, d1 and d2 ml methods, ${ }^{12}$. Comments in this Section will be focused only on the comparison between $\mathrm{d} 1$ and $\mathrm{d} 2 \mathrm{ml}$ methods. The comparison between $\mathrm{d} 0$ and $\mathrm{d} 2 \mathrm{ml}$ does reinforce the same conclusions obtained below.

Table 2 reports time spent ${ }^{13}$ by each of the three ml methods in achieving the models' convergence. ${ }^{14}$ Results from Table 2 highlight two relevant differences between $\mathrm{d} 1$ and $\mathrm{d} 2 \mathrm{ml}$ methods: Firstly, d2 method significantly reduces time required to achieve the all models convergence. Differences in time required seem to be less evident in the estimation of single risk models: for instance, for fitting the two mass-points model, d2 (d1) method needs 46 seconds (6.28 minutes). However it becomes more important as both the number of risks and the number of mass-points increase: for fitting the three competing risks model with four mass-points, d2 method only requires 8.02 minutes, whereas d1 method needs 1.58 hours. On its part, d0 method not even achieve the model convergence:

\footnotetext{
${ }^{12}$ The all estimations, whose time required are shown in Table 2, include a set of twenty eight covariates that, as results shown in Section 5, control for duration dependence, personal characteristics, type of labor contract, regional effects and economic cycle. The detailed estimation results are available upon request to the interested reader.

${ }^{13}$ I work with Stata 14.0 MP - Parallel edition 64 bits. The machine employed to obtain estimation results incorporates an Intel(R) Core(TM) i7-6700HQ CPU at 2.60 GHz, and 12 Gb RAM memory. The operating system is Windows 10 Home.

${ }^{14}$ In this sample composed of youth Spanish employees, the estimation of five points of support for the identification of the non-parametric unobserved heterogeneity distributuion is not possible, neither fitting single risk models, nor competing riks models.
} 
Table 2: Time required for the estimation of multispell competing risks duration models (Sample size: 1,316,611 observations)

\begin{tabular}{|c|c|c|c|c|c|}
\hline & \multicolumn{5}{|c|}{ Time (hh:mm:ss) } \\
\hline & d0 method & d1 method & d2 method & Diff. $=\mathrm{d} 1-\mathrm{d} 2$ & Diff. $=\mathrm{d} 0-\mathrm{d} 2$ \\
\hline \multicolumn{6}{|l|}{ Single risk } \\
\hline Two mass-points & $1: 37: 59$ & $0: 06: 28$ & 0:00:46 & 0:05:42 & 1:32:17 \\
\hline Three mass-points & 3:00:16 & $0: 12: 48$ & 0:02:03 & $0: 10: 45$ & 2:49:31 \\
\hline Four mass-points & $18: 02: 16$ & 0:21:01 & 0:06:52 & 0:14:09 & $17: 48: 07$ \\
\hline \multicolumn{6}{|l|}{ Two risks } \\
\hline Two mass-points & $3: 59: 59$ & $0: 20: 10$ & $0: 01: 48$ & $0: 18: 22$ & $3: 41: 37$ \\
\hline Three mass-points & $7: 58: 44$ & $0: 37: 28$ & 0:04:00 & $0: 33: 28$ & $7: 25: 16$ \\
\hline Four mass-points & $7: 03: 51$ & $0: 58: 28$ & 0:07:06 & $0: 51: 22$ & $6: 12: 29$ \\
\hline \multicolumn{6}{|l|}{ Three risks } \\
\hline Two mass-points & $3: 45: 53$ & $0: 40: 09$ & $0: 03: 19$ & $0: 36: 50$ & $3: 09: 03$ \\
\hline Three mass-points & - & $1: 13: 42$ & $0: 05: 43$ & $1: 07: 59$ & - \\
\hline Four mass-points & - & $1: 58: 29$ & 0:08:02 & $1: 50: 27$ & - \\
\hline
\end{tabular}

after eleventh iteration, it gets into a backed up loop. Secondly, unlike d2 method, time required by $\mathrm{d} 1$ method to achieve the model convergence strongly dependes both on the number of exits modeled, and on the number of points of support for the identification of the UH. Table 2 shows that, using d2 (d1) method, the difference in time spent between the less time-demanding model (the single risk model with two mass-points) and the most time-demanding model (the three competing risks with four mass-points) reaches 7.16 minutes (1.52 hours).

\section{Concluding remarks}

This article presents hsmlogit, a new Stata command that estimates multispells discrete time competing risks duration models with unobserved heterogeneity. hsmlogit allows for the estimation of one, two and up to three competing risks, as well as a maximum of five points of support for the identification of the nonparametric unobserved heterogeneity distribution [Heckman and Singer, 1984]. The relevance of modelling more than one risk has been highlighted by estimating the effect of apprenticeship contracts on a sample composed of low educated young workers in the Spanish labor market for the period 2000-2014. Thus, the estimation of a three competing risks duration model has been the only way to find out the potential effect of public financial incentives for the conversion of apprenticeship contracts into open-ended ones on the direct (via job-to-job) transition rates towards an open-ended contract. Moreover, since hsmlogit allows for the estimation of non-parametric UH distribution ([Heckman and Singer, 1984]), 
our results capture the presence of two types of workers with different values of unobserved characteristics that affect the estimated hazard rates.

Finally, hsmlogit provides the algebraic expressions of both the gradient vector and the Hessian matrix, which significantly reduces time required to achieve the model convergence, and also improves the standard errors' accuracy of the estimated coefficients. The possibility of estimating competing risks duration models with the presence of UH, along with time savyings provided by the use of $\mathrm{d} 2 \mathrm{ml}$ method may allow the applied researchers to easily and properly exploit the richness and complexity of large longitudinal microdata sets.

\section{References}

[Abbring and Van den Berg, 2004] AbBring, JaAp H. And VAn Den Berg, GERARD J., Analysing the effect of $d y$ namically assigned treatments using duration models, binary treatment models, and panel data models, Empirical Economics, January 2004, Volume 29, Issue 1, pp. 5-20.

[Allison, 1982]

Allison, Paul D., Discrete-Time Methods for the Analysis of Event Histories, Sociological Methodology, Vol. 13 (1982), pp. 6198.

[Arranz, García-Serrano and Hernanz, 2013] Arranz, J.M., GarcíaSerrano, C. And Hernanz, V., 2013, How do we pursue ?labormetrics?? An application using the MCVL, Estadística Española, Vol. 55 (2013), No. 181, pp. 231-254.

[Arranz and García-Serrano, 2011] Arranz, J.M. And García-Serrano, C., 2011, Are the MCVL tax data useful? Ideas for mining, Hacienda Pública Española, Vol. 199(4), pp. 151-186.

[García-Pérez, 2008]

García-PÉrez, J.I., 2008 La Muestra Continua de Vidas Laborales: Una guía de uso para el anlisis de transiciones, Revista de Economía Aplicada, N. E-1, Vol. XVI, pp. 5-28.

[Gaure, Roed and Zhang, 2007] Gaure, S., Roed, K. And Zhang, T., 2007 Time and causality: A Monte Carlo assessment of the timing-of-events approach, Journal of Econometrics, Volume 
[Gould et al., 2010]

[Heckman and Singer, 1984]

[Jenkins, 1995]

[Lancaster, 1992]

[Lapuerta, 2010]

[Troncoso-Ponce, 2016]

[Troncoso-Ponce, 2017]

[Van Den Berg, 2001]
141, Issue 2, December 2007, Pages 11591195.

Gould, W., Pitblado, J. and Poi, B., Maximum Likelihood Estimation with Stata, Fourth Edition, Stata Press, 2010.

Heckman, J. J. And Singer, B., A Method for Minimizing the Impact of the Distributional Assumptions in Econometric Models for Duration Data, Econometrica, Vol. 52, pp. 271-320.

[Jansen and Troncoso-Ponce, 2017] Jansen, M. and Troncoso-Ponce, D., The impact of apprenticeship contracts on the labour market insertion of youth in Spain, Fedea working paper (forthcoming).

Jenkins, S., 1995 Easy Estimation Methods for Discrete-Time Duration Models, Oxford Bulletin of Economics and Statistics, Vol. 57, 1, 1995.

LANCASTER, TONY, The Econometric Analysis of Transition Data, First Edition, Cambridge University Press, 1992.

Lapuerta, I. (2010) Claves para el trabajo con la Muestra Continua de Vidas Laborales, DemoSoc working paper (2010-37), Universitat Pompeu Fabra

Troncoso-Ponce, D., 2016 An empirical analysis of some public policies applied to the Spanish labour market, $\mathrm{PhD}$. Thesis, Chapter 3.

Troncoso-Ponce, D., 2017 Faster estimation of discrete time duration models using hshaz2, Manuscript. Available at: https://ideas.repec.org/p/pab/wpaper/17.05.html

Van Den Berg, Gerard. J, 2001 Duration models: specification, identification, and multiple durations, Handbook of Econometrics, Elsevier, Vol. 5, 2001, pp. 33813460 . 